SUPPLEMENTARY INFORMATION

\title{
Chemoplasmonic Oscillation: A Chemomechanical Energy
}

\section{Transducer}

\author{
Fangfang Deng†, Jiajin Feng‡ and Tao Ding ${ }^{*}$
}

†. Key Laboratory of Artificial Micro- and Nano-structures of Ministry of Education of China, School of Physics and Technology, Wuhan University, Wuhan 430072 China.

‡. School of Physics, Sun Yat-sen University, Guangzhou 510275 China.

Email: t.ding@whu.edu.cn 


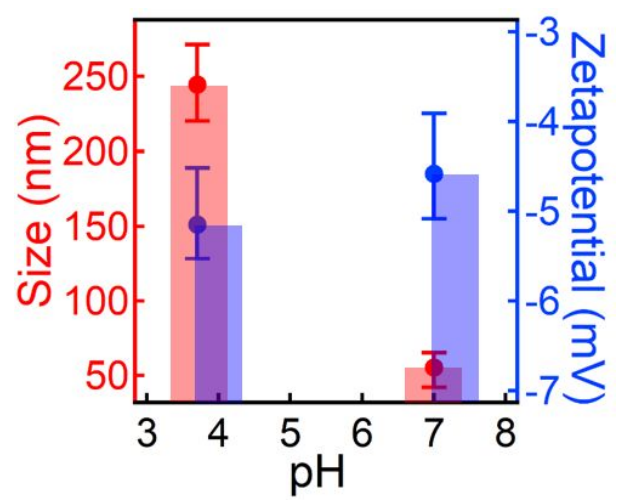

Figure S1. Hydrodynamic sizes and zetapotentials of Au NP@PNIPAM at pH of 3.7 and 7.0.
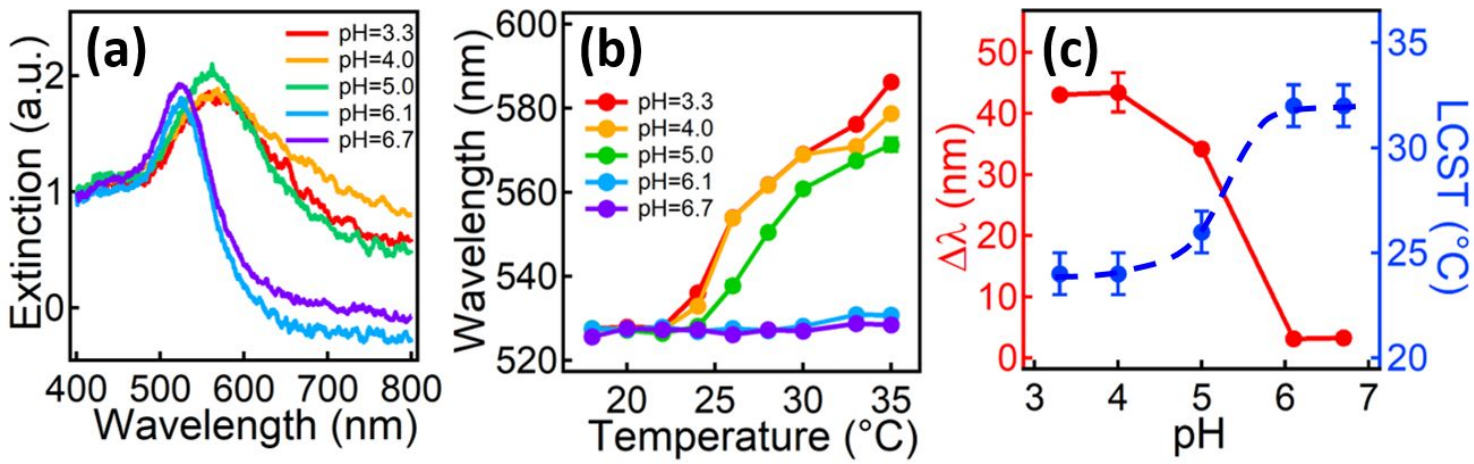

Figure S2. (a) UV-Vis spectra of Au NP@PNIPAM at $30{ }^{\circ} \mathrm{C}$ with different pH. (b) Change of plasmon resonances with temperature at different $\mathrm{pH}$ condition. (c) Change of plasmon shift $(\Delta \lambda)$ and LCST with $\mathrm{pH}$.
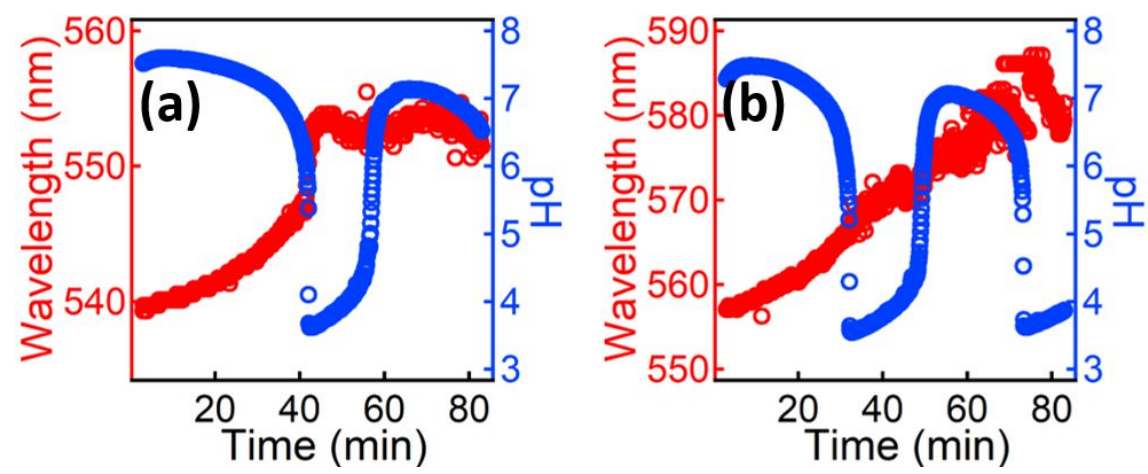

Figure S3. Change of plasmonic resonances with pH oscillation. The Au NPs size is (a) $60 \mathrm{~nm}$ and (b) $80 \mathrm{~nm}$. 


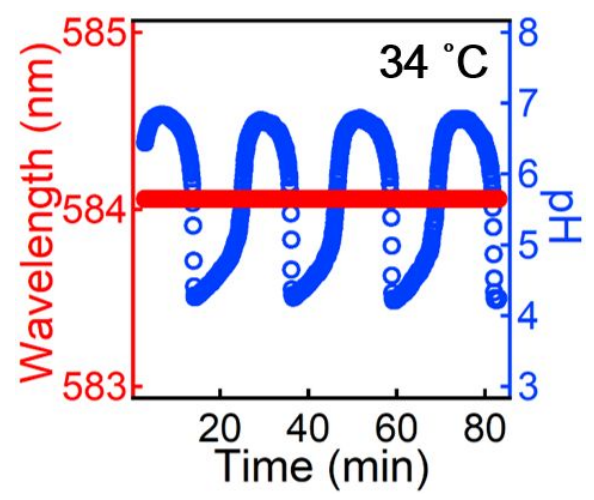

Figure S4. Chemoplasmonic and $\mathrm{pH}$ oscillations at $34^{\circ} \mathrm{C}$ with the injection rate of $2.6 \mu \mathrm{L} / \mathrm{min}$.
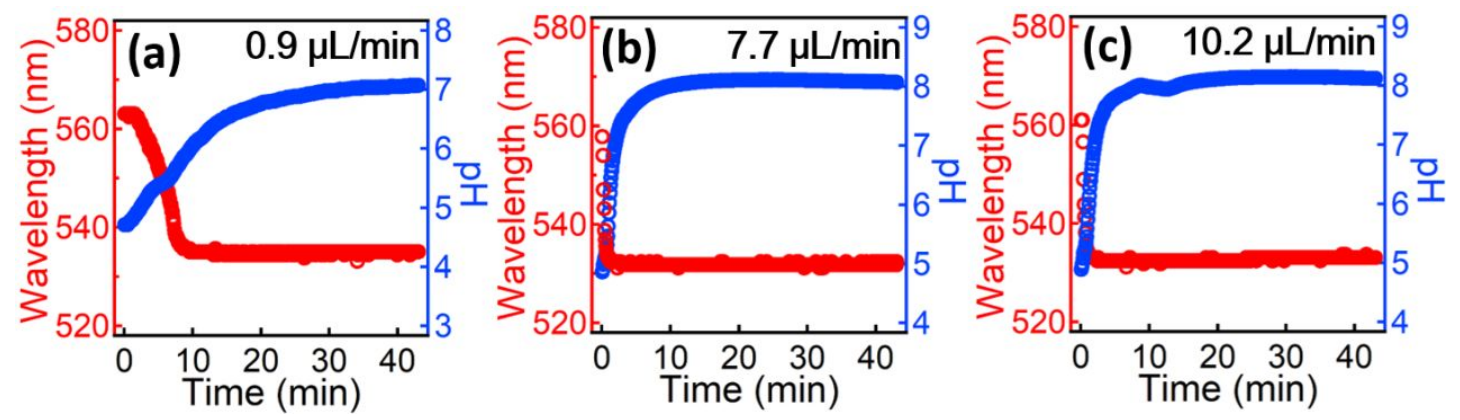

Figure S5. Chemoplasmonic and $\mathrm{pH}$ oscillations at different injection rate of Solution B. (a) 0.9 $\mu \mathrm{L} / \mathrm{min}$ (b) $7.7 \mu \mathrm{L} / \mathrm{min}$, (c) $10.2 \mu \mathrm{L} / \mathrm{min}$. All the reaction temperature is stabilized at $28^{\circ} \mathrm{C}$.

\section{Redox potential calculation}

\section{Redox reaction:}

$\mathrm{BrO}_{3}^{-}+6 \mathrm{H}^{+}+6 e^{-} \rightarrow \mathrm{Br}^{-}+3 \mathrm{H}_{2} \mathrm{O}$

$\mathrm{MnO}(\mathrm{OH})^{+}+3 \mathrm{H}^{+}+2 e^{-} \rightarrow \mathrm{Mn}^{2+}+2 \mathrm{H}_{2} \mathrm{O}$

$\mathrm{HS}_{2} \mathrm{O}_{6}^{-}+\mathrm{H}^{+}+2 e^{-} \rightarrow 2 \mathrm{HSO}_{3}^{-}$

The redox potential of each chemical reaction can be calculated by using Nernst equation:

$$
\varphi=\varphi^{0}+\frac{2.30 R T}{n F} \lg \frac{(O x)^{m}}{(\operatorname{Red})^{q}}
$$

where $\varphi^{0}$ is the standard electrode potential of each chemical reaction, which are $1.478 \mathrm{~V}$, $1.23 \mathrm{~V}$ and $0.569 \mathrm{~V}$ for reaction $(\mathrm{a}),(\mathrm{b})$ and $(\mathrm{c})$, respectively. $\mathrm{R}$ is the gas constant $(8.314$ $\mathrm{J} / \mathrm{mol} \cdot \mathrm{K}), \mathrm{T}$ is the temperature $(301 \mathrm{~K}), \mathrm{F}$ is Faraday's constant (96500 J/ V· mol), $\mathrm{n}$ is the number of transferred electrons in the chemical reaction. Ox and Red refer to the concentration of oxidants and reductants respectively. $\mathrm{m}$ and $\mathrm{q}$ represent the stoichiometric number of the reaction. 


\section{Energy efficiency estimation}

The release of elastic energy $(\Delta \mathrm{E})$ happens when the $\mathrm{pH}$ increases (consumption of $\mathrm{H}^{+}$ions) with the following reaction

$\mathrm{MnO}(\mathrm{OH})^{+}+2 \mathrm{HSO}_{3}^{-}+2 \mathrm{H}^{+} \rightarrow \mathrm{Mn}^{2+}+\mathrm{HS}_{2} \mathrm{O}_{6}^{-}+2 \mathrm{H}_{2} \mathrm{O} \quad \mathrm{E}=0.38 \mathrm{~V}$

For unit molar, the Gibbs free energy of this reaction is $\Delta G_{m}=-n F E=-73 \mathrm{~kJ}$

In the $\mathrm{pH}$ oscillation system, the $\mathrm{pH}$ changes from 3.7 to 7 , from which we can calculate the number of $\mathrm{H}^{+}$ions that take part in the redox reaction around the Au NP as,

$$
N_{p}=c_{H}+V_{\text {pnipam }} N_{A}
$$

where $c_{H^{+}}$is the concentration of proton $\left(10^{-3.7}\right), V_{\text {pnipam }}$ is the volume of PNIPAM coated around Au NP. $N_{A}$ is Avogadro constant. The result suggests approximately one proton per Au.

Then the Gibbs free energy for the $\mathrm{H}^{+}$consumption is $\Delta \mathrm{G}=\Delta G_{m} / N_{A}=\sim-29 \mathrm{kT}$, which drives the release of elastic energy of PNIPAM $(10 \mathrm{kT})$. So the energy efficiency of this system is $10 \mathrm{kT} / 29 \mathrm{kT}=\sim 34 \%$. 